\title{
Leverage points for improving gender equality and human well-being in a smallholder farming context
}

\author{
Aisa O. Manlosa ${ }^{1} \cdot$ Jannik Schultner ${ }^{1} \cdot$ Ine Dorresteijn ${ }^{2} \cdot$ Joern Fischer $^{1}$
}

Received: 8 June 2018 / Accepted: 29 September 2018 / Published online: 10 October 2018

(c) The Author(s) 2018

\begin{abstract}
How transformative processes could be facilitated to improve gender equality and consequently, human well-being, is a key question for moving towards a just and sustainable future. Focusing on southwestern Ethiopia where significant changes in formal institutions related to gender have occurred, we applied the concept of systemic leverage points. We show that changes in formal structures facilitated changes in perceived visible gender gaps, such as increased participation of women in public activities. These, in turn, played an enabling role for changes in community norms, and (to a lesser degree) triggered reconsideration of perceptions about women's capacities. Both women and men perceived more equal gender relations as being associated with better well-being at the household level. Our results highlight the important role of interactions between leverage points for gender equality, suggesting important insights can be gained by studying interactions, compared to when shallow (e.g., visible gaps) or deeper leverage points (e.g., social norms) are analyzed in isolation. Our study also demonstrated the general suitability of a leverage-points perspective in gender research, including as an analytical frame to complement gender transformative approaches.
\end{abstract}

Keywords Gender equality $\cdot$ Leverage points $\cdot$ Sustainability $\cdot$ Transformative change $\cdot$ Institutions $\cdot$ Sustainable development

\section{Introduction}

Gender equality has the dual role of being a valued end in itself and a means for sustainable development (Sen 1999; UN General Assembly 2015). Despite decades of effort, gender inequality persists, both in the so-called global north and global south (Bose 2015; World Economic Forum 2017). Effecting transformative change that addresses the root causes of gender inequality remains a largely unresolved challenge (Hillenbrand et al. 2015; Risman 2004). Conceptual shifts in the gender and development discourse (Razavi and Miller 1995) have critiqued the Women-In-Development

Handled by David J. Abson, Leuphana Universitat, Luneburg, Germany.

Aisa O. Manlosa

aisamanlosa@gmail.com

1 Faculty of Sustainability, Leuphana University Lueneburg, Universitätsallee 1, 21335 Lueneburg, Germany

2 Copernicus Institute of Sustainable Development, Utrecht University, Utrecht, Netherlands
(WID) approach for its narrow neoliberal focus, and for missing to engage with institutions that create and entrench patterns of advantages and disadvantages (Okali 2011). These critiques behove broadening the analytical frame through which gender should be analyzed. Few studies have systematically analyzed the roles and interactions of different domains of changes related to gender (e.g., McDougall 2017). Here we use the notion of leverage points - flagged as a potentially powerful metaphor and analytical tool in sustainability science (Abson et al. 2016; Meadows 1999) — to examine how institutional changes targeting visible gender gaps might interact with changes in norms and attitudes, potentially creating ripple effects and thereby new opportunities for navigating towards a sustainable, gender-equal future (Njuki et al. 2016).

A distinct conceptual shift in the gender and development discourse has emphasized the role of social norms, attitudes, behaviors, practices, and power imbalance as underlying drivers of (or levers for changing) gender inequality (Kantor 2013; McDougall et al. 2015). Rooted in feminist ideology, this framing underpins gender transformative approaches, applied in sectors such as health (Dworkin 
Fig. 1 Conceptual framework of leverage points for improving gender equality and household well-being

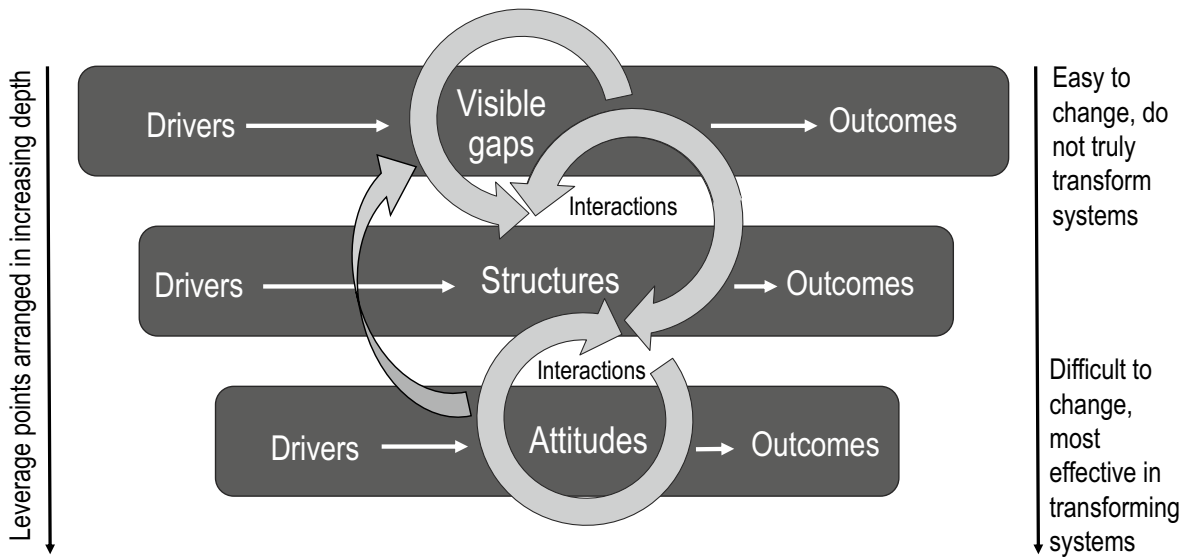

et al. 2012), smallholder agriculture (Farnworth et al. 2013; Njuki et al. 2016), and aquatic agricultural systems (Cole et al. 2014b). The point of departure for this approach is the function of deep drivers shaping more visible aspects of gender inequality, as well as other types of social inequality. Inherent complexity in processes of social change suggests that deep changes occur through a confluence of factors that eventually reshape a social trajectory (Kabeer 1999). This suggests that interventions focusing on visible gaps, though not transformative per se, do play a role (e.g., Lavers 2015). Here, we sought to build a broad understanding of different leverage points for gender equality. As a complement to the gender-transformative perspective, which addresses and challenges how norms and attitudes shape gender inequalities, our investigation considers the manifold interactions between changes in formal institutions, visible gaps, and gendered norms and attitudes. We hypothesize that while transformative change requires a shift in deep drivers of gender inequality, institutional changes for addressing visible gaps and changes in such gaps can potentially contribute to processes of change in the deeper realms of norms and attitudes (Dejager and Jayasinghe 2016).

We focused on southwestern Ethiopia where the shift of government power from the Derg regime to the current government placed the promotion of women's rights on the national political agenda (Crewett and Korf 2008; Kumar and Quisumbing 2015). Within this context, we drew on qualitative data from three kebeles (smallest administrative unit in Ethiopia) to (1) examine gender-related changes from a leverage-points perspective; (2) determine factors driving the observed changes and identify associated household well-being outcomes; and (3) understand interactions between shallow and deep-leverage points for gender-related changes.

\section{Conceptual framework: leverage points as interacting domains for interventions for gender-transformative change}

Interventions in complex systems (social systems included) are possible at different leverage points. Meadows (1999) conceptualized leverage points as places to intervene in a system, with varying levels of depth or effectiveness for changing the functioning of a system. Abson et al. (2016) distilled four realms of leverage, namely parameters, feedbacks, design, and intent, in order of increasing depth. Here we defined leverage points as domains for interventions that can result in observable changes within a system. We adopted the framing by Abson et al. (2016) and translated it into a conceptual lens for analyzing factors that produce, mark, and entrench gender inequality within communities (Fig. 1).

In the conceptualization of leverage points for sustainability, shallow leverage points are areas where "interventions are relatively easy to implement yet bring about little change to the overall functioning of a system" (Abson et al. 2016). These include parameters and feedbacks. Parameters are tractable characteristics of a system commonly targeted by policy makers. In gender and development, these take the form of visible gaps, and are often addressed through direct interventions. Examples of visible gender gaps include gendered disparity in education (Davies and Saltmarsh 2007; Klasen and Lamanna 2009), gendered income differences (Bobbitt-Zeher 2007), and differences in the proportion of men and women participating in economic, political and other public activities (Assaad and Arntz 2004; Elson 1999; Walby 1994). Examples of interventions to address such gaps include 
income-generating projects for women (Chowdhury et al. 2018), or quotas (Van der Windt et al. 2018). Visible gaps are important markers of inequality, but they are symptomatic and therefore point to underlying dynamics (Kabeer 1999).

Deep leverage points are a system's structures and encapsulated intent (Abson et al. 2016). We used the term structures to refer to both formal and informal institutions or rules governing social practices (Hillenbrand et al. 2015). For example, policies are types of formal institutions, while social norms are informal rules. Intent is the deepest realm of leverage, spanning the values, goals, and worldviews of actors from which the trajectory of a system emerges. Due to the limited scope of our investigation, in this realm we focused only on attitudes, which we defined as entrenched ways of thinking about men's and women's ways of doing and being (e.g., Rani et al. 2004). Finally, we also included feedbacks in our framing. Our focus here was not on feedbacks between parameters (Abson et al. 2016), but on interactions across leverage points. We aimed to understand how interventions at different types of leverage points, and different system changes, interact (e.g., Waylen 2013).

In applying this conceptual framework for analysis, we were guided by two considerations. First, our focus was empirical rather than theoretical (Risman 2004). Our understanding of leverage points and their interactions therefore, was based on the most salient dynamics that emerged from the focal system. Second, we subscribed to the notion of primacy of context (Flyvberg 2001). Hence, we considered the framework as a lens to explore the socioeconomic and political fabric of a given social system, with recognition of likely different dynamics in other contexts.

\section{Methods}

Our study was situated in southwestern Ethiopia and included three kebeles (lowest administrative unit in Ethiopia) in three woredas or districts, namely Gumay, Setema, and Gera. The area is home to the Oromo people, the largest ethnic group in the country. The majority of the population in the study area are Muslims. This strongly influences rules and practices relating to gender roles in private and public spheres and gender-differentiated inheritance practices, particularly in relation to land. Superimposed on a patriarchal sociocultural fabric is a political will for the promotion of women's rights. This political will manifests in reform in land registration, reform in family code covering issues such as settlement of capital assets in case of divorce or death of husband (Kumar and Quisumbing 2015), and intentional inclusion of women in activities such as livelihood-trainings and community meetings.
Table 1 Focus group discussions in three kebeles

\begin{tabular}{lll}
\hline Kebele & Men's FGDs & Women's FGDs \\
\hline Kuda Kofi & 1 Relatively poor & 1 Relatively poor \\
& 1 Relatively rich & 1 Relatively rich \\
Difo Mani & 1 Relatively poor & 1 Relatively poor \\
& 1 Relatively rich & 1 Relatively rich \\
Kela Harari & 1 Mix of poor and rich & 1 Mix of poor and rich \\
\hline
\end{tabular}

Our analysis drew on qualitative data from three activities, namely key informant interviews (KIIs, $n=15$ ), focus group discussions (FGDs, $n=10$ ), and semi-structured interviews (SSIs, $n=15$ ). KIIs with residents who had lived in the kebeles for at least 20 years were designed to generate a contextual understanding of the sociocultural and economic context. We used a well-being ladder (sensu Petesch et al. 2018) as a tool for arriving at a contextualized characterization of worse-off and better-off men and women. This elicited characteristics of individuals from various socioeconomic strata. Our questions covered livelihoods, capital assets, relationships, and broader changes in the communities. Information from the KIIs was used to inform the selection of FGD participants. In addition, the semi-structured interviews were intended to explore individual experiences in relation to the themes that emerged from the FGDs. FGDs (44 men and 41 women; Table 1) were designed to investigate gender dynamics in the area in the last 10 years. We probed perceptions about gender norms surrounding livelihoods, access and control of capital assets, relationships and participation in public activities, among others. We also explored narratives of factors driving these changes and associated well-being outcomes at the household level. In addition, semi-structured interviews were conducted to substantiate and corroborate themes that emerged from FGDs, drawing on the narratives of individuals' lived experiences. All participants were identified through locally hired field guides aided by suggestions from other local residents. FGDs and interviews with women were conducted with a female translator, and data collection activities with men were conducted with a male translator. All conversations were recorded, transcribed, and translated into English.

Prior to data collection, we met with community leaders and members to explain the purpose of the research. Moreover, each interview and FGD started with explaining the reasons why participants were invited to the conversation, the general themes to be covered, an estimate of time the activity would take, confidentiality, and a request for permission to record. Local residents were informed that they were free to refuse to answer any question and to leave the conversation whenever they wished to. We also communicated the study and sought permission from different levels of government 
(i.e., regional, woreda, and kebele levels). Ethics approval was duly obtained.

Qualitative data from the three above-mentioned activities were subjected to content analysis using NVivo (NVivo QSR 2016). In total, we did three rounds of iterative coding combining deductive and inductive approaches. In the first round, we developed a coding tree based on the main themes and structure of the data collection instruments-coding themes included broad sociocultural, economic, and political context; prevalent gender norms; and decision-making processes. The original coding tree was then expanded with new codes to capture nuances in the responses. In the second round of coding, we refined the coding tree based on the gender-related changes that emerged as the most important narratives in the data. In the third round of coding, we coded the perceived changes using leverage points as a conceptual lens to analyze the observed changes, drivers, and attendant outcomes associated with interventions, for different leverage points and their interactions. This involved classifying identified changes as a change in visible gap, a change in formal or informal structure, a change in attitude, or an interaction between leverage points.

\section{Results}

We present our findings with respect to gender inequalities, perceived changes, factors driving changes and perceived importance for household well-being (Table 2). The first subsection deals with visible gaps, structures and attitudes; and the second subsection deals with interactions among these three domains. We focused on those gender-related changes that were central to the discussions of local residents. Due to the general agreement in the narratives of better-off and worse-off men and women, we aggregated narratives from the three kebeles as below.

\section{Domains of gender inequalities and changes}

\section{Visible gaps}

A clear gendered differentiation exists in the study area, both in the private sphere of the household and the public sphere of community. Visibly, this differentiation manifested in the types of activities that individuals engaged in. For example, undertaking livelihoods for the production of food or the generation of income, and representation of households in public activities such as meetings and trainings related to livelihoods, and natural resource conservation have traditionally been considered the responsibility of men. Women have traditionally been responsible for maintaining the home and caring for children. Food preparation was almost exclusively women's responsibility, and this involved heavy pounding of food crops such as teff and sorghum to separate grain, bringing crops to (an often distant) milling station, and cooking. In the words of a female interviewee: "The role of women is to deliver food to their husbands in the field."

Circumscribed responsibilities created notions of acceptable and unacceptable things to do. For example, it was common for men to be the only ones responsible for livelihood activities and this intertwined with male dominance in decision-making for the use capital assets and types of crops to plant. Women were commonly not allowed by their husbands to attend public meetings and trainings_- "There was no meeting for women, no equality. Husbands did not allow women to join meetings or go elsewhere." (Female FGD participant). Such an exclusion is crucial because community-level deliberations and transmission of information concerning important matters such as livelihoods improvement, natural resources, and accessing government services occurred in those public meetings and trainings. Construction of tacit gender roles for men and women in effect privileged men's control of livelihood strategies and representation of his household to the wider community. Women's responsibilities circumscribed within the home essentially closed off opportunities for proactive and productive engagement in livelihoods and public dialogue. Low physical mobility because of responsibilities at home, fear of being raped, and the potential stigma of breaking normative rules traditionally further limited any possibility of engagement in livelihoods and formal public activities.

Exclusion from livelihoods and public activities were related. Strict responsibilities between livelihoods as men's and domestic care as women's provided justification for women's limited mobility outside the home and their absence in public meetings. Consequently, their being restricted to homes and their inability to access information and meaningfully participate in community dialogues constrained the building of their capacities and agency.

Notwithstanding this traditional situation and its continuation until today, in the last 10 years, women have become more visible in public meetings, trainings related to livelihoods and natural resource conservation (i.e., not related to gender issues per se), and involvement in conservation activities such as the construction of soil terraces to prevent erosion. The change was described as: "Ten years ago, women were not involved in meetings. We had no right to decide on matters. There was no awareness. But now, we are involved in meetings and we receive advice. We are now aware about our rights and we can get involved in livelihood activities. We have a big range of rights including education, sending our children to school and being involved in important things when needed." (Female FGD participant). The importance of women's ability to appear and participate in public meetings was related with improvements in their physical mobility and participation in livelihood activities. "Women 


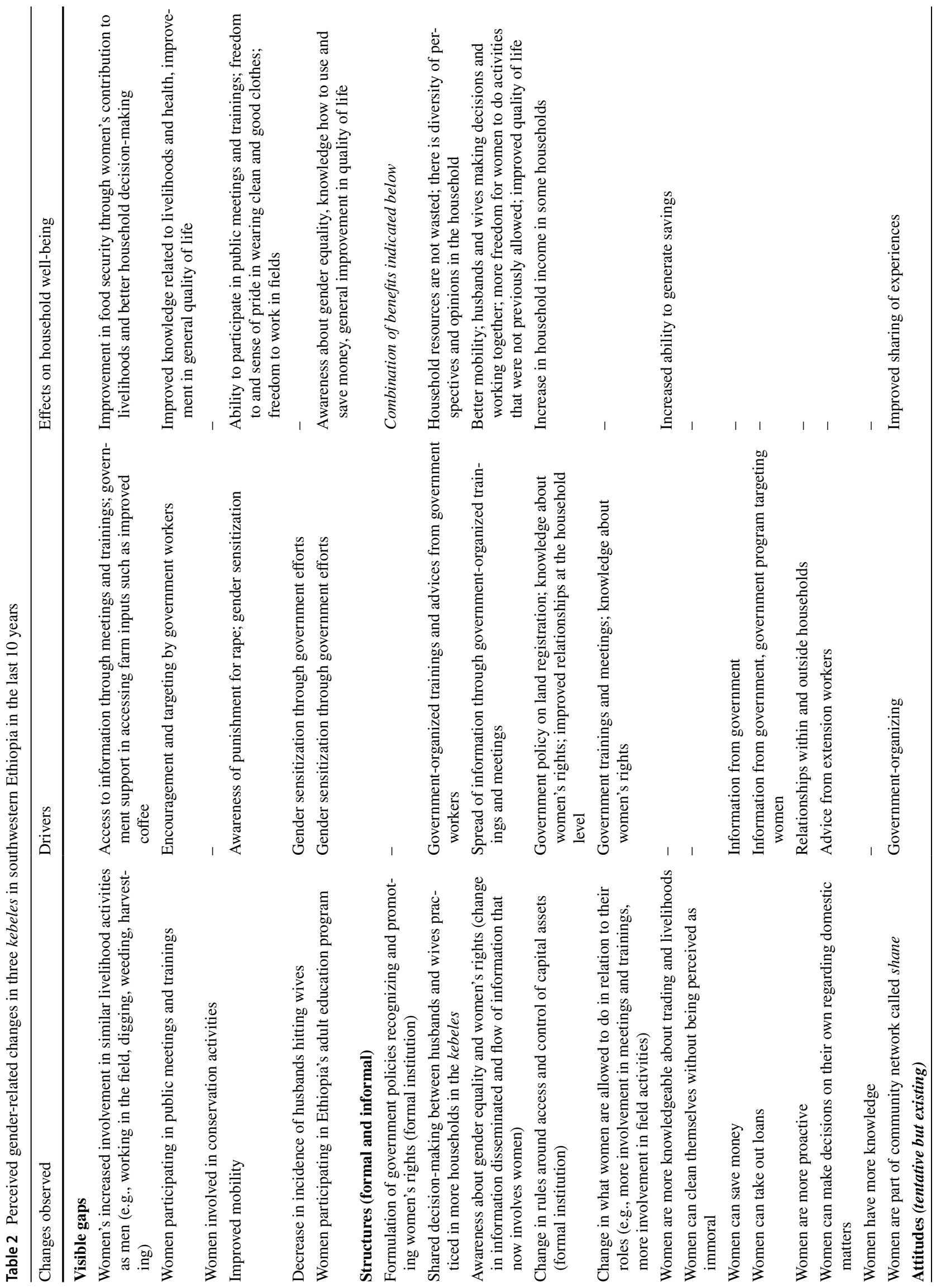




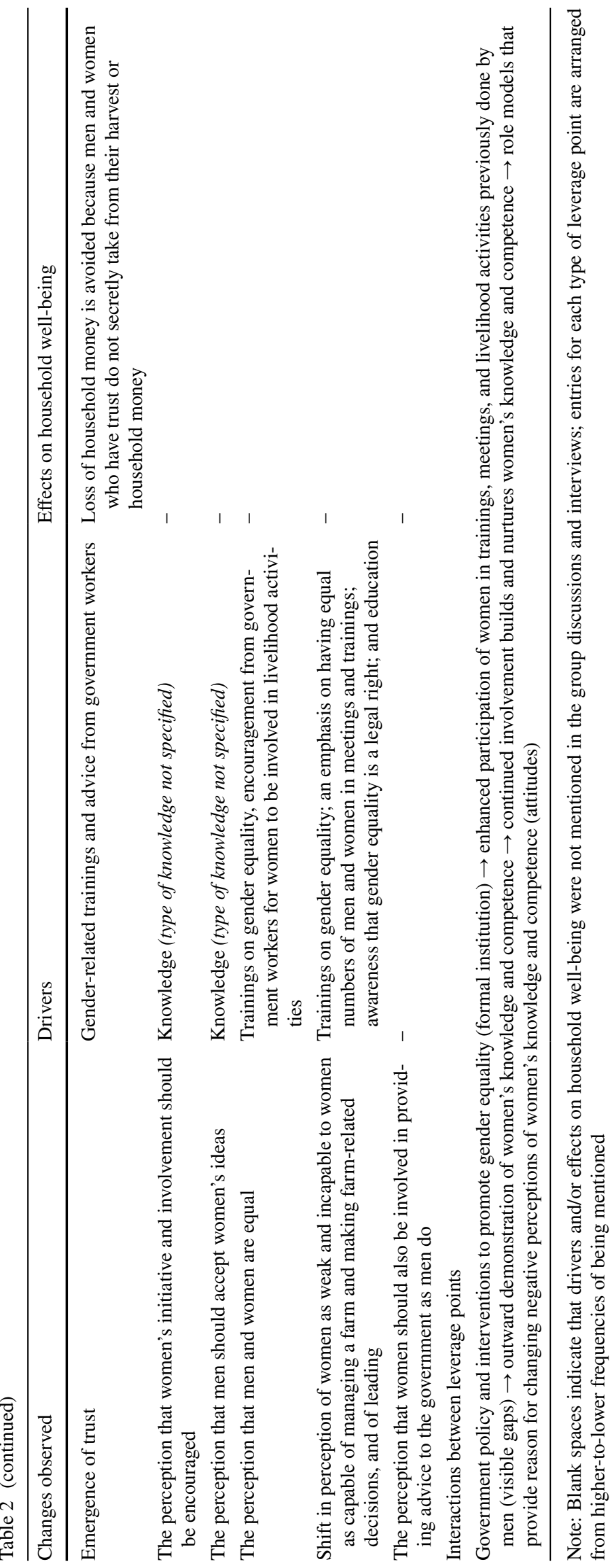


were not allowed to join meetings or go elsewhere. But now, women work in the fields as the husbands do. We wash our bodies, wear nice clothes and join meetings without restrictions by the husbands." (Female FGD participant).

In the private sphere similarly, there had been a perceived change in gendered livelihood participation. While ploughing remained strictly men's work because of the heavy labor required, more women were becoming involved in farm-field activities such as digging, weeding, and harvesting. In some cases, women were responsible for deciding harvest allocation for consumption, selling, and seeds. Some women managed seed-keeping. More women were proactively involved in trading and in generating income from home gardens. "Nowadays, women work hard and improve their lives, such as through coffee propagation in home gardens and planting in the fields with men. Compared with the past, women used to stay in the house and wait for everything from their husbands." (Female interviewee).

State policy and intervention for promoting women's rights were identified as key factors driving these changes in visible gaps. Particular changes included information dissemination to increase awareness of women's rights, explicit encouragement of women to attend meetings and trainings, and emphasis on the importance of women's participation in public activities and livelihoods. One participant identified criminalization of rape as a factor supporting women's improved mobility saying: "Women were afraid to work far from their husbands because they may be exposed to the risk of rape. But nowadays, people are aware that the punishment for that is heavy. So women can freely move and work on activities to improve the quality of their lives." (Male FGD participant).

In terms of outcomes, these visible changes were perceived to be beneficial for household food security and quality of life. Knowledge acquired through these changes "contributed to how households worked, how households kept healthy, and to a general improvement in the quality of life." (Male FGD participant). According to another male participant, the mechanism for contributing to an improvement in food security was through increasing yields. This became possible because advice received from development agents encouraged women's involvement in decision-making concerning livelihood activities. A male FGD participant described the change process as follows "This came after the fall of the Derg regime and start of the current government, which initiated equality of women and men. Before, women didn't know about equality and about decision-making. Husbands controlled all. The new policy encouraged women to work as men. If they cannot plow, they can do other types of work in the fields." This was perceived to have a positive effect on the use as well as the generation of household resources. "This change positively affects the food security of households, by increasing yields and improving the quality of life. Through advice, people's understanding increases, this facilitates women's involvement in decision-making for livelihood activities. This also supports an increase of resources and income sources to live a good quality of life." (Male FGD participant). Moreover, a female FGD participant described the effect on their household as positive because "even if one's husband does not work hard, we can earn through trading and work in the fields to secure food for our families." The importance of women's involvement in public activities and livelihoods was succinctly captured in the statement "If a man works alone, it is impossible to bring development." (Male FGD participant).

\section{Structures and rules}

Clear changes in formal institution can be traced back to the shift of government power from the Derg (1974-1991) dictatorship to the ruling Ethiopian People's Revolutionary Democratic Front (EPRDF) (1991 onwards). Changes in visible gaps discussed in the preceding subsection including women's visibility in public meetings and trainings and in farm-field activities were consistently attributed to government policies and interventions promoting women's rights. An example of this is requiring the inclusion of wives' and children's names in the registration of land. This provided household members a legal claim to land in the event of divorce or death of the male household head. However, whether the policy reform on land registration influenced women's livelihoods was less clear. Changes in women's livelihood involvement were mainly attributed to a clear message from the government during local meetings and trainings concerning women's equal capacities, and not necessarily to a change in formal rules concerning land entitlement. In fact, despite the presence of legal provision for women's rights to inherit land, or to retain their share of land in the event of a husband's death or divorce, the enforcement of these formal rules was still contingent on women contesting de facto access to land which sanctioned the claim of other men (sons from first wives or relatives). Retaining land after divorce or a husband's death was viewed as requiring a specific character described as "a woman who can describe her problems very well, even in front of the law. She's not shy but strong. She can get ruling from the court. So the people cannot touch her property because she has knowledge." (Female FGD participant). In terms of inheritance, without daughters staking their claims in court-and this was uniformly the case-land customarily went to sons. It was implicit to this patriarchal social arrangement that women would access land mainly through marriage. Notably, women from some of the poorest households were not aware of this policy reform, and most of the poorest households did not have land at all, closing off opportunities for 
the communities' poorest to directly benefit from this change in a formal institution.

Social norms that codify acceptable ways of doing and being, for men and women are collectively held and imbibed. Therefore, early shifts in informal structure are likely to be fragmented at best, involving a tension between notions of what is acceptable and what is not. Owing in part to a long history of female repression, normative changes in southwest Ethiopia are emerging as a redefinition of what women can do. There was no evidence for a parallel change in what men can do or be. However, men had been similarly involved in processes of change through the views they hold concerning what women can do in households and in communities. In our investigation, informal structures or the normative domain had the most numerous changes identified relative to other domains, though these changes were rather tentative.

Gender norms in the area, including the basic sphere of self-care, had been rather restrictive. For example, women who observed hygienic practices were perceived as being immoral. Presently however, women can practice self-care such as washing themselves and wearing clean clothes without being viewed as doing a "morally bad" action.

In terms of being informed, women's general state of knowledge and awareness was perceived to have improved due to improved access to basic and adult education and participation in public activities. Their attendance in meetings and trainings had the effect of altering the flow of information, making some information directly accessible to women, where previously, information (e.g., related to farming, health) reached women mainly through their husbands. However, while women participated more frequently in meetings and trainings, it was not clear whether their voices were equally heard, and in many cases their participation still required approval by their husbands- "We share information from the meeting to our wives and she pays attention to it. We also allow them to participate in meetings so they acquire knowledge. She can then say, 'We have to teach our families and bring about quality of life.' Ten years ago, men didn't allow women to participate in meetings." (Male FGD participant). Participation in public gatherings also provided women with opportunities to meet and establish relationships with other women, which became venues for informal sharing of experiences and ideas-activities that women valued as opportunities for learning.

Concerning roles and responsibilities in the households, strict gender lines continue to divide men and women. However, a shift in informal rules about what women can do has started to expand women's scope of activity. In relation to having greater freedom to participate in public activities and farm-field activities, women are now allowed to save money, take out loans, and participate in community networks with other households. Perhaps the most significant normative shift within the households is located within the relationship between husbands and wives. A clear change was perceived in the dynamics of household decision-making, from being the sole responsibility and right of men, to one that is shared between men and women. Local residents estimated that this type of shared decision-making was practiced by about a quarter of the population 10 years ago and that this had increased to about three-quarters of households in our study area. However, in shared decision-making processes, women's involvement could be either practical or strategic. ${ }^{1}$ In many cases, men remained as the initiator of discussions and women's contribution related mainly to providing information for the households' food needs. Yet there were also examples of women taking a more strategic role in the decision-making process by initiating discussions and negotiating the use of capital assets and livelihoods.

Factors identified as influencing these changes included government interventions as described in the subsection of visible gaps, access to information and improved knowledge, and improved relationships between men and women at the household level. The improvements in relationships were perceived to have been positively influenced by women's involvement in public meetings, trainings and livelihood activities. Women's involvement had an effect on knowledge and a sense of confidence, which in turn contributed to better communication. "We discussed prior to trainings. But after trainings, discussions were sweet and deep-it's like when someone is hungry and eats food. Something without education and training is not sweet." (Male interviewee). In terms of outcomes, shared decision-making between husbands and wives were perceived as having a positive influence on household income and were seen by both men and women to lead to a general improvement in the quality of life. The mechanism for this was described as "...the husband harvests and puts it in storage while the wife tells him the proportion of the harvest that should be enough for consumption. If he wants to sell the crops when the crops allocated for consumption is not enough, the wife can refuse and reason out that the allocation is not enough for food. Our decision and discussions are examples to our children... If there is disagreement, on one hand the wife would sell, on the other hand the husband would sell and they run out of crops. Finally, the children are left without food..." (Female FGD participant).

\footnotetext{
${ }^{1}$ Strategic involvement in decision-making involves having a voice in the determination of goals, means, and valued outcomes. It involves setting directions. On the other hand, practical involvement in decision-making is less substantive and often involves providing needed information, and acquiescence to goals already set by another party (see Kabeer 1999 on agency).
} 


\section{Attitudes}

Conceptions of gender roles and responsibilities are often predicated on notions about men and women's innate characteristics. In the context of our study area, women were mainly responsible for domestic matters not merely because of a perceived caring nature but because of a perceived lack of knowledge, lack of foresight and management abilities, and lack of competence for productive engagement in livelihoods. This was exemplified by the statements "In the past, people said women can't do anything. They are weak. They have no energy, and no capacity." (Male FGD participant) and "In the past, there was no involvement in anything, they [women] were not even considered as human beings." (Female interviewee). Against the matrix of these settled ways of thinking, women who exemplified knowledge, ability, and initiative contributed to a general reshaping of how women were perceived. In fact, several male FGD participants considered that women could be leaders and should have greater involvement in providing inputs to the government for planning development. "Not only men, women too should be involved in giving advice to government and in working as men do to bring development or improvement." (Male interviewee). A relatively similar comment but relating to the household said “As women accept men's ideas, it is better if we accept their ideas and plans. This opinion comes from knowledge." (Male FGD participant). Factors identified to facilitate such shifts in attitudes were improvement in knowledge and awareness of gender equality through trainings and government advice, and improvements in relationships between men and women through better communication. This improvement in communication was linked to an increase in shared decision-making, which in turn, was facilitated by government efforts to include women in meetings and trainings, and encouraged their participation in livelihoods. A small but significant number of women role models who showcased their abilities and generated beneficial outcomes for themselves and their households may also be providing a positive rebuttal to the dominant narrative of women being incapable. Interestingly, some women who were perceived as "doing gender" differently by taking more proactive involvement in livelihoods were migrant settlers coming from a different part of the country.

In some households where women were perceived as capable, there had been an emergence of trust between husbands and wives. However, the mechanisms at work that led to a positive perception of women's capacities are not clear. This positive perception could be present in households where men had been socialized in more gender-equal ways of thinking. On the other hand, women's display of capacities may be met with negative treatment. A response to a hypothetical scenario of a proactive wife setting up her own livelihood in a big city was that of another man telling

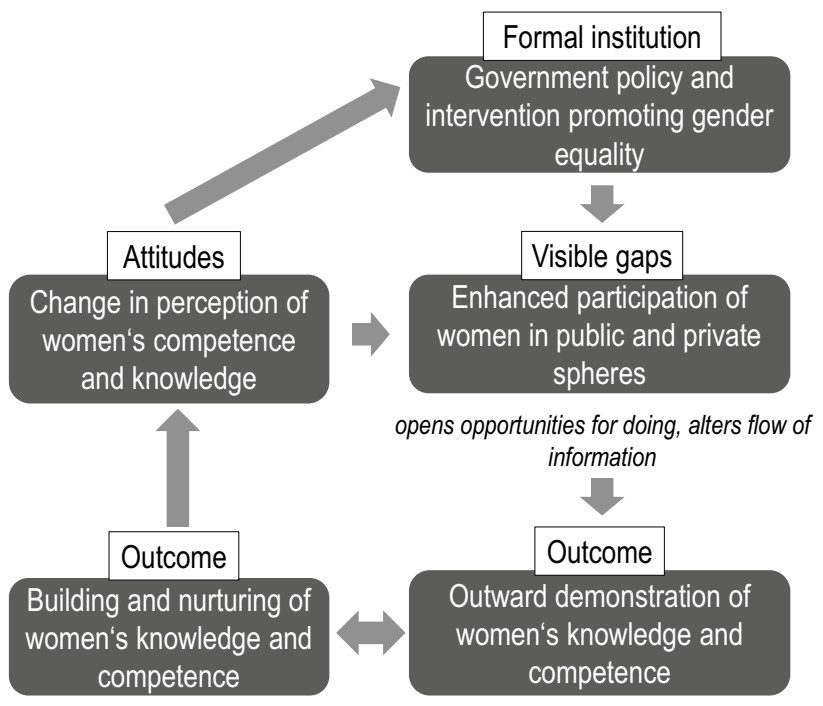

Fig. 2 Interactions between leverage points for gender-transformative change in southwestern Ethiopia

the husband "Are you following her? What is she doing? Who is the household head-you or her? You are foolish." (Female FGD participant).

Trust was considered beneficial for households because it prevented the loss of crops and income. In the absence of trust, men took from household resources for their personal use and women would do the same for the needs of their respective household_- "Nowadays, both husbands and wives decide together how to use their capital assets. In the past, there was no agreement nor trust between men and women and money was lost." (Male interviewee). Mutual trust was perceived to facilitate working together towards shared goals and better use of household resources.

\section{Interactions between leverage points}

Above, we discussed changes in three realms of leverage-visible gaps, structures, and attitudes-and briefly introduced the drivers of these changes and their outcomes for human well-being. Overall, we found evidence that changes at different levels of depth interacted and facilitated one another. While changes at deep-leverage points drive the overall trajectory of a system, our findings suggest that changes at shallow-leverage points created important "sparks" that contributed to enabling conditions for deeper changes. Here, we present our understanding of the mechanisms by which a change in formal institutions interacted with social norms and attitudes towards women in southwest Ethiopia (Fig. 2).

The formal institutional change and interventions observed rarely explicitly challenged unequal gender norms. However, gender-aware policy reforms and interventions 
served to open opportunities for women to undertake actions that were otherwise socially unacceptable. Formal institutional change thus provided legitimacy to an alternative manner of doing, which previously lacked local acceptance. The tightly linked changes between formal institutions and visible gaps then apparently catalyzed a re-imagination of what women can do, albeit these new "freedoms to do" are still deeply constrained by patriarchal informal institutions. To name some tangible changes, rules concerning saving money, taking out a loan, and being part of a network of households changed. For example, where before women were not customarily allowed to hold more than $100 \mathrm{birr}$ (equivalent to roughly 4 USD), they now can. "In the past, women had no right to save money_could not have more than 100 birr-but now women are involved in taking out loans from the government." (Female FGD participant).

Crucially, as women have become more visible and able to participate in public and private spheres, their opportunities for engaging in livelihoods and participating in public activities have become more accessible. "Ten years ago, women were not involved in meetings, had no right to decide, and no awareness. But now women are involved in meetings and they get advice. So they are aware about their rights and are involved in livelihood activities." (Female FGD participant). This is important, not so much as an ultimate marker of improvement in gender equality, but as a window of opportunity to demonstrate knowledge and capacity in areas where women traditionally had been perceived as lacking. Participation served as an antithesis to the belief that women are weak, incapable, and ignorant-whether this belief was held by men, or by women themselves who had internalized this in their identity construction. "The government advised us and trained us about the equality of men and women. The government called equal numbers of men and women to meetings. They told us that women can do everything - if she can't plough the land, she can use daily wage labor to do that. For example, women who have no husbands work their fields using paid labor. They prepare seeds and fertilizers as men. The government encouraged women to work equally as men and trained both men and women about fairness. For example, a woman can be a leader or a vice chairman. This is the right given by the constitution or government. In the past, people said women can't do anything... but no." (Male FGD participant).

Moreover, as mentioned earlier but worth noting again in this section about interactions, the above-mentioned changes in visible gaps altered the flow of information, enabling women to access some information by themselves rather than through their husbands. This indicates that a change in visible gaps had an effect on structure, particularly the flow of information. Opportunities to do things differently built knowledge and competence in areas previously closed off to women such as farming livelihoods, and in turn, enabled them to further demonstrate knowledge and competence in these areas. Through this, perception about women's capacities has begun to change. This can potentially inform further changes in formal institutions (Fig. 2).

\section{Discussion and conclusion}

Gender equality is elemental to a just and sustainable world. It is also instrumental for improved livelihoods and food security (Kerr 2005; Lemke and Bellows 2016). The need for gender-transformative change that permeates social systems-from deep-seated attitudes, to social structures and processes, to the closing of visible gaps for instrumental purposes, is clear (UN General Assembly 2015). Our analysis of gender dynamics in the context of southwest Ethiopia contributes insights for facilitating transformative change. We showed that gender inequality, interventions, and corresponding changes could be observed in the domains of visible gaps, structures, and attitudes, and that interactions between these domains are crucial for ongoing systemic change (Fig. 2). Particularly, we showed how, in a context where there were no interventions that directly challenged gender-unequal norms, policy change and efforts to address visible gaps between men and women contributed to the creation of enabling conditions for changes in norms and attitudes. In this section, we discuss (1) the contextual significance of formal institutional change in southwest Ethiopia; (2) the role of reflection for amplifying interactions between leverage points and for orienting change towards gender equality; and (3) the added value of a leverage-points perspective to assist development and research organizations to systematically engage with transformative change.

Empirical analyses of gender-transformative change often involve mechanisms of change precipitated by interventions designed to target deep-leverage points by identifying, addressing, and challenging those (i.e., social structures, norms, and belief systems) (e.g., Sarapura Escobar et al. 2016). An excellent example is the household methodologies (HHM) piloted by Oxfam Novib in coffee-producing villages in Uganda (International Fund for Agricultural Development 2014). Using HHM, household members worked together to develop a vision for the future, identified steps to realize the vision, and held reflexive conversations to trace factors that held households back from the kind of life they desired. Another example is a microcredit project piloted by WorldFish in collaboration with other organizations in the Barotse floodplain in Zambia to engage with unequal gender norms. Women's access to microcredit was used as a platform for understanding and challenging entrenched inequalities in gendered access and control of resources (Cole et al. 2014a). In many contexts, however, such creative and sustained interventions targeting deep-leverage points are absent. 
Indeed, while innovative social interventions by development practitioners and researchers are important to facilitate change, Razavi and Miller (1995) observed that the "state still remains responsible for regulating macrolevel forces in a more gender-equitable manner". Locked in an autocratic and repressive regime with little scope for challenging unjust treatment for decades, liberalization of government and consequent policy reforms became one of the key drivers of gender dynamics in Ethiopia. This suggests that in certain contexts, if government institutions undergo transformation in policies, language, and practice among others, the potential to create knock-on effects at lower sociopolitical levels is high (Branisa et al. 2012). In our study area, the shift of formal institutions in favor of gender equality motivated changes in the belief systems of some men and women. However, Lavers (2015) cautions that while policy reforms in Ethiopia were intended for effective policy implementation including for gender equality, political concerns and evident desire of the state to dominate the Oromo ethnic group should be recognized. His nuanced analysis of the effect of land registration on community gender dynamics in Ethiopia showed that though reform affected women's land rights positively, different customary practices across different contexts mediated the actual effects of the reform. For example, norms on labor allocation left women disadvantaged despite their recognized formal rights to land.

In our study, while gender inequality remained pervasive, positive changes were observed at shallow-leverage points, which in turn expanded women's scope of freedom. The same logic underlies Dejager and Jayasinghe's (2016) reasoning as they explored how gender may be integrated in aquaculture development in Nepal. They commented that while certain initiatives may not directly challenge social norms and practices, these "can also be transformative as women take on new responsibilities and new decision-making, negotiating, and leadership roles". Moreover, households with more gender-equal relations were perceived to also have better general well-being. These households provide local examples and inspiration for change (Kandiyoti 1988). Attention to these changes does not preclude a deeper and critical investigation of the way changes in the domain of visible gaps may mask underlying inequality, or the way a change in policy may leave a social norm unchallenged, thus entrenching patterns of inequality. Indeed, in our investigation, the perceived changes in informal rules were alterations of rules concerning what women are allowed to do, rather than a substantive reconfiguration of gender roles and redistribution of power. At their worst, women's expanded "freedoms to do", dispatched for altruistic purposes for household and community, may entail an increase in labor burden that further disadvantage women (e.g., Doss 2001). This is a well-known reality. Yet, alternatively, such changes can be seeds that form the basis for intentional engagement with deeper leverage points for transformation.

Interactions between leverage points suggest opportunities for amplifying desirable change and for facilitating processes that more deliberately engage with deeper leverage points. Reflection is key to this, in the form of both individual practice and collective practice through critical conversations (Sarapura Escobar et al. 2016). Reflection involves creating ample time and safe space for asking questions and coming to one's own answer concerning specific matters. In the context we studied, most of the changes observed at the level of visible gaps were a result of government intervention-something that was imposed, rather than a result of internal deliberation and local choice. Yet this process of deliberation involving articulation of what changed, from whose perspective, whether the change was beneficial or not and for whom, and why, is important for fostering local ownership of change processes (Cole 2018, personal communication). In many cases including southwest Ethiopia, external factors induce a change in practice (e.g., livelihood involvement, attendance at public meetings). Yet practices may change without necessarily altering long-held views, such as men being natural leaders, or women being ignorant and incapable. The reflexive question why-whether and why a certain change is good; whether and why a certain change should be maintained or reverted-is critical for transforming social systems. A small number of people rethinking women's capacities for thought and action constitutes positive change, but a transformed social system implies that new ways of being and doing are embodied by the majority of people. Individual reflection can facilitate the rethinking of gendered norms and attitudes, while collective reflections can foster debates and expand the scope of change (Galiè and Kantor 2016).

Transformative change is theorized as being multi-scalar and involving multiple stakeholders. Changes at the level of formal institutions and policies are mediated by various contextual factors before they translate into change in the lived experiences of households and individuals. On the other hand, changes located within the limited scope of individuals' lives or a group's do not lead to transformation unless higher level and more widespread structures and processes are fundamentally altered. Transformation thus involves all three elements: widespread change in what is visible, in the institutions and rules that govern and create visible conditions, and the deeply held views of individuals or organizations. Devkota et al. (2016) called attention to "the interaction between actors and structures that causes change in a dynamic and cyclical process". For a massive challenge such as transformative change towards gender equality, including its intersection with other inequality-causing factors, research and development organizations continue to be constrained by the scope and modes 
of operations. Most organizations seeking to address wicked problems such as food insecurity and poverty lock in on interventions at the household level. On the other hand, organizations seeking to make an impact at higher levels such as that of policy-making sometimes miss to deeply engage with households for whom policies are supposed to make a difference. The notion of leverage points provides a framework for systematically engaging with key areas for gender-transformative change. It explicitly considers interactions between leverage points. This, in turn, increases the prospect that changes at the level of structures and processes will translate to changes in daily-lived experiences; and conversely, that changes in individual's ways of being and doing will challenge entrenched structures of power. The over-arching goal of applying leverage points as an analytical lens for facilitating gender-transformative change is not unlike the gender transformative approaches such as the one operationalized by WorldFish in the Barotse flood plain (Cole et al. 2014b). However, a key contribution of a leverage points lens is its explicit incorporation of different levels of leverage and explicit consideration of interactions between these. This provides scope for capturing both deeply entrenched inequalities and emerging positive changes. Often, positive changes are observed and measured in the service of justifying the value of an intervention. A leverage-points perspective, in contrast, takes ongoing changes as the dynamic material that change-makers must work with. On the basis of our findings, we call attention to a need for further research on interactions between leverage points for gender equality, rather than a focus only on visible gaps or only deeper leverage such as social norms. Furthermore, this study showed the suitability of a leverage-points perspective for the analysis of gender-related changes-as such, it can complement more established facets of gender transformative approaches, which address and challenge social norms and attitudes shaping gender inequalities. Finally, in our study, positive changes provided counter examples that starkly contrasted with typical gendered modes of being and doing. These provided local people the material with which to re-imagine possibilities and alternatives. These existing (albeit fragmented) changes are potential seeds for transformative change and thus, good starting points for charting a course towards a gender-equal future.

Acknowledgements We thank the local residents of the three kebeles for sharing their time and thoughts. Thanks to: Feyera Senbeta for facilitating institutional arrangements for the field work; to Kristoffer Hylander for helpful conversations in the field; to Dadi Feyisa and Tolani Asirat for translating; and to Steven Michael Cole and Rebecca Freeth for reading an earlier draft and providing insightful comments. Two anonymous reviewers provided helpful comments and suggestions, which further improved the manuscript. This study was made possible by a European Research Council Consolidator Grant to JF.

\section{Compliance with ethical standards}

Conflict of interest We declare that there are no competing interests involved in this work.

Open Access This article is distributed under the terms of the Creative Commons Attribution 4.0 International License (http://creativeco mmons.org/licenses/by/4.0/), which permits unrestricted use, distribution, and reproduction in any medium, provided you give appropriate credit to the original author(s) and the source, provide a link to the Creative Commons license, and indicate if changes were made.

\section{References}

Abson DJ, Fischer J, Leventon J, Newig J, Schomerus T, Vilsmaier $\mathrm{U}$, von Wehrden $\mathrm{H}$, Abernethy P, Ives CD, Jager NW, Lang DJ (2016) Leverage points for sustainability transformation. Ambio 46:30-39. https://doi.org/10.1007/s13280-016-0800-y

Assaad R, Arntz M (2004) Constrained geographical mobility and gendered labor market outcomes under structural adjustment: evidence from Egypt. World Dev 33:431-454. https://doi. org/10.1016/j.worlddev.2004.08.007

Bobbitt-Zeher D (2007) The gender income gap and the role of education. Sociol Educ 80:1-22

Bose C (2015) Patterns of global gender inequalities and regional gender regimes. Gend Soc 29:767-791. https://doi.org/10.1177/08912 43215607849

Branisa B, Klasen S, Ziegler M (2012) Gender inequality in social institutions and gendered development outcomes. World Dev 45:252-268. https://doi.org/10.1016/j.worlddev.2012.12.003

Chowdhury SA, Chowdhury MF, Ahmed M (2018) Engaging rural women in entrepreneurship through an innovative and sustainable dairy model. In: Leal FW, Mifsud M, Pace P (eds) Handbook of lifelong learning for sustainable development. World Sustainability Series. Springer, Cham, pp 257-275. https://doi. org/10.1007/978-3-319-63534-7_18

Cole SM, Kantor P, Sarapura S, Rajaratnam S (2014a) Gender transformative approaches to address inequalities in food, nutrition, and economic outcomes in aquatic agricultural systems in lowincome countries. CGIAR Research Program on Aquatic Agricultural Systems, Penang

Cole SM, van Koppen B, Puskur R, Estrada N, DeClerck F, BaiduForson JJ, Remans R, Mapedza E, Longley C, Muyaule C, Zulu F (2014b) Collaborative effort to operationalize the gender transformative approach in the Barotse floodplain. CGIAR Research Program on Aquatic Agricultural Systems, Penang

Crewett W, Korf B (2008) Ethiopia: reforming land tenure. Rev Afr Polit Econ 35:203-220. https://doi.org/10.1080/0305624080 2193911

Davies B, Saltmarsh S (2007) Gender economies: literacy and the gendered production of neo-liberal subjectivities. Gend Educ 19:1-20. https://doi.org/10.1080/09540250601087710

Dejager T, Jayasinghe C (2016) From capture to culture: Space for mainstreaming women in coastal aquaculture development in Sri Lanka. In: Parkins JR, Kaler A, Njuki J (eds) Transforming gender and food security in the Global South. Routledge, UK, pp 49-75

Devkota R, Khadka K, Gartaula H, Shrestha A, Karki S, Patel K, Chaudhary P (2016) Gender and labor efficiency in finger millet production in Nepal. In: Parkins JR, Kaler A, Njuki J (eds) Transforming gender and food security in the Global South. Routledge, UK, pp 76-95 
Doss C (2001) Designing agricultural technology for African women farmers: lessons from 25 years of experience. World Dev 29:2015-2092. https://doi.org/10.1016/S0305-750X(01)00088-2

Dworkin SL, Hatcher AM, Colvin C, Peacock D (2012) Impact of a gender-transformative HIV and antiviolence program on gender ideologies and masculinities in two rural, South African communities. Men Masc 16:181-202. http://journals.sagepub.com https ://doi.org/10.1177/1097184X12469878

Elson D (1999) Labor markets as gendered institutions: equality, efficiency and empowerment issues. World Dev 27:611-627. https:// doi.org/10.1016/S0305-750X(98)00147-8

Farnworth C, Sundell MF, Nzioki A, Shivutse V, Davis M (2013) Transforming gender relations in agriculture in Sub-Saharan Africa. Swedish International Agricultural Network Initiative, Stockholm

Flyvberg B (2001) Making social science matter: why social inquiry fails and how it can succeed again. Cambridge University Press, Cambridge

Galiè A, Kantor P (2016) From gender analysis to transforming gender norms: using empowerment pathways to enhance gender equity and food security in Tanzania. In: Parkins JR, Kaler A, Njuki J (eds) Transforming gender and food security in the Global South. Routledge, UK, pp 189-216

Hillenbrand E, Karim N, Mohanraj P, Wu D (2015) Measuring gendertransformative change: a review of literature and promising practices. CARE USA, Atlanta

International Fund for Agricultural Development (2014) Household methodologies: harnessing the family's potential for change. IFAD, Rome

Kabeer N (1999) Resources, agency, achievements: reflections on the measurement of women's empowerment. Dev Change 30:435-464. https://onlinelibrary.wiley.com https://doi. org/10.1111/1467-7660.00125

Kandiyoti D (1988) Bargaining with patriarchy. Gend Soc 2(3):274290. https://doi.org/10.1177/089124388002003004

Kantor P (2013) Transforming gender relations: key to positive development outcomes in aquatic agricultural systems. CGIAR Research Program on Aquatic Agricultural Systems, Penang

Kerr RB (2005) Food security in northern Malawi: gender, kinship relations and entitlements in historical context. J South Afr Stud 31:53-74. https://doi.org/10.1080/03057070500035679

Klasen S, Lamanna F (2009) The impact of gender inequality in education and employment on economic growth: new evidence for a panel of countries. Fem Econ 15:91-132. https://doi. org/10.1080/13545700902893106

Kumar N, Quisumbing A (2015) Policy reform toward gender equality in Ethiopia: little by little the egg begins to walk. World Dev 67:406-423. https://doi.org/10.1016/j.worlddev.2014.10.029

Lavers T (2015) Land registration and gender equality in Ethiopia: how state-society relations influence the enforcement of institutional change. J Agrar Change 17:188-207. https://onlinelibrary.wiley .com https://doi.org/10.1111/joac.12138

Lemke S, Bellows AC (2016) Sustainable food systems, gender, and participation: foregrounding women in the context of of the right to adequate food and nutrition. In: Bellows AC, Valente FLS, Lemke S, de Nunez Burbano Lara MD (eds) Gender, nutrition, and the human right to adequate food: toward an inclusive framework. Routledge, UK, pp 254-340

McDougall C (2017) Gender and system research: leveraging change. In: Öborn I, Vanlauwe B, Phillips M, Thomas R, Brooijmans W, Atta-Krah K (eds) Sustainable intensification in smallholder agriculture: an integrated systems research approach. Taylor \& Francis, New York, pp 275-288

McDougall C, Cole SM, Rajaratnam S, Brown J, Choudhury A, KatoWallace J, Manlosa A, Meng K, Muyaule C, Schwarz A, Teioli H (2015) Implementing a gender-transformative research approach: early lessons. In: Douthwaite B, Apgar JM, Schwarz A, McDougall C, Attwood S, Senaratna Sellamuttu S, Clayton T (eds) Research in development: learning from CGIAR Research Program on Aquatic Agricultural Systems. CGIAR Research Program on Aquatic Agricultural Systems, Penang, Malaysia, pp 41-56

Meadows D (1999) Leverage points: places to intervene in a system. The Sustainability Institute, Vermont

Njuki J, Parkins JR, Kaler A, Ahmed S (2016) Gender, agriculture, and food security: where are we? In: Parkins JR, Kaler A, Njuki J (eds) Transforming gender and food security in the Global South. Routledge, UK, pp 1-18

NVivo Qualitative Data Analysis Software (2016) QSR International Pty Ltd. Version 11

Okali C (2011) Achieving transformative change for rural women's empowerment. In: Enabling rural women's economic empowerment: institutions, opportunities and participation. UN Women

Petesch P, Badstue L, Prain G (2018) Gender norms, agency, and innovation in agriculture and natural resource management: the GENNOVATE methodology. CIMMYT, Mexico

Rani M, Bonu S, Diop-Sidibe N (2004) An empirical investigation of attitudes towards wife-beating among men and women in seven Sub-Saharan African countries. Afr J Reprod Health 8:116-136. http://www.jstor.org/stable/3583398

Razavi S, Miller C (1995) From WID to GAD: conceptual shifts in the women and development discourse. United Nations Research Institute for Social Development, Geneva

Risman B (2004) Gender as a social structure: theory wrestling with activism. Gend Soc 18:429-450. https://doi.org/10.1177/08912 43204265349

Sarapura Escobar SS, Odame HH, Thiele G (2016) Gender and innovation in Peru's native potato market chains. In: Parkins JR, Kaler A, Njuki J (eds) Transforming gender and food security in the Global South. Routledge, UK, pp 160-185

Sen A (1999) Development as freedom. Anchor Books, New York

UN General Assembly (2015) Transforming our world: the 2030 agenda for sustainable development. United Nations, New York

Van der Windt P, Humphreys M, de la Sierra R (2018) Gender quotas in development programming: null results from a field experiment in Congo. J Dev Econ. https://doi.org/10.1016/j.jdeveco.2018.02.006

Walby S (1994) Is citizenship gendered? Sociology 28:379-395. https ://doi.org/10.1177/0038038594028002002

Waylen G (2013) Informal institutions, institutional change, and gender equality. Polit Res Q 20:1-12. https://doi.org/10.1177/10659 12913510360

World Economic Forum (2017) The global gender gap report. World Economic Forum, Geneva 